\title{
Landscape architecture and novel ecosystems: ecological restoration in an expanded field
}

\author{
Catharina Sack
}

\begin{abstract}
Within the continuum of natural-to-novel ecosystems - i.e., from the 'pristine' to the greatly intervened - this paper emphasizes the role of design within highly modified ecosystems in areas of urbanization. It is argued that, as certain landscapes (particularly urbanized ones) can never be restored to original levels of historical ecological fidelity, they should be treated as both cultural and ecological landscapes. It is then proposed that these anthropogenic landscapes would be ready canvases for designed (or planned) novel ecosystems that could be inculcated with ecological function and systems delivery, yet having profound aesthetic manipulation. Based on this landscape architecture perspective, it is suggested that ecologists may not have fully explored cultural interventions in restoring landscapes, especially within the agency of design. A design strategy for the biological hotspot of Perth in southwestern Australia is then provided as a relevant example of how novel ecosystems can be designed. Without an acute and novel approach to modifying current development practices, Perth's biodiversity is on track for considerable deterioration. From this exploratory backdrop, it is elaborated how neo-baroque design strategies can be used for structuring ecological systems to create resilient and productive novel ecosystems grounded in a critical and autochthonous aesthetic of botanical complexity.
\end{abstract}

Keywords: Landscape architecture; Novel ecosystem design; OCBIL landscapes; Urban ecology; Translational strategies

\section{Review \\ Introduction \\ "..[We] need to acknowledge that restoration is fundamentally a design practice." Higgs}

Integrating novel ecosystems (vs. historical ones) as endpoints for ecological restoration has contentiously been proposed as a potential and more realistic outcome for addressing the seemingly unavoidable dilemma of 'restoring' ecosystems (sensu strictu) within the Anthropocene ${ }^{\mathrm{a}}$. In this regard, much of the debate has justifiably centred around the viewpoint of biological conservation and environmental stewardship, and, e.g., whether novel ecosystems could represent innovative planning or a lowering of the bar for standards of restoration. As part of the multidisciplinary discourse endorsed by this journal, this paper approaches the debate from an altogether different field by elaborating on existing novel ecosystems from the perspective of landscape architecture, whereby these systems are viewed as

Correspondence: tinka.sack@uwa.edu.au

Faculty of Architecture, Landscape and Visual Arts, University of Western Australia, M433, 35 Stirling Highway, Crawley, WA 6009, Australia platforms for cultural (human) engagement. Certain novel ecosystems (particularly those interfacing with modern urbanism) could be viewed as purposefully designed landscapes, which encompass both cultural and ecological values.

In addressing the design of novel ecosystems, landscape architecture represents an allied field in attempts to create and define translational strategies in the restoration of ecological function (Musacchio 2009). Within its own aesthetic discourse, landscape architecture has evolved from one of scenographic intent (i.e., where the view or scene is the aesthetic driver) towards that of a systematic aesthetic based in McHargian roots (i.e., at times referred to as 'eco revelatory' in which landscape systems are the aesthetic driver) (Thayer 1998; Windhager et al. 2010; Howett 1998; McHarg and Mumford 1969) $)^{\mathrm{b}}$. And so, under the assumption of an ecological continuum ranging from near-natural or 'wild' landscapes, having historic and ecological fidelity, to highly intervened and altered landscapes, which require extensive human management to sustain their ecological function, this paper focuses on the latter; more specifically, the decidedly modified and often erased ecosystems resulting from urbanization. This paper then proposes that these 
altered landscapes are a ready canvas for designed novel ecosystems to be inculcated with ecological function and systems delivery, yet having profound aesthetic manipulation (Figure 1). It is suggested that ecologists may not have fully explored cultural interventions when attempting to restore disturbed landscapes, particularly within the agency of design. While this contribution may appear atypical for conventional ecological forums, the design discipline of landscape architecture may offer translational strategies for engaging and valuing human participation in ecological restoration by expanding the debate surrounding novel ecosystems to allied fields.

\section{Designed ecology - novel ecosystems in an expanded field \\ Translational strategies}

The disciplines of ecology and biological conservation have recently attempted to articulate the benefits of design as a relevant cultural and aesthetic endeavour (Barrett et al. 2009a; Gobster et al. 2007). In this regard, Barrett et al. (2009b) and Felton and Pickett (2005) advocate creating ecological 'designed experiments' where public landscapes are created by melding analysis and aesthetics, and studied collaboratively by both ecologists and designers (Felson and Pickett 2005). Within the distinct fields of landscape architecture and landscape ecology, there is a seeming desire for a merger of ideas and goals; but such a merger is far from being explored exhaustively. Musacchio (2009) proposes an avenue of translational research as 'a collaborative learning process between scientists, designers, planners and engineers who seek to solve complex environmental problems by connecting scientific theory, concepts, and principles to the design and planning of the built environment.' In keeping the discourses separate, hazards of language and methodologies are revealed. For example, in landscape architecture, there is a risk of designing 'green-washed' landscapes, whereby ecosystems are veneers of ecology, created without sufficient consideration for the necessary requirements and complexity of self-sustaining, stable and locally appropriate ecosystems. Whereas, within ecology, landscape design risks becoming a management plan rather than a synaesthetic cultural endeavour (Haila 2007), undervaluing the potential of human interaction and subsequent values created. In many of these endeavours, the translation is typically and unilaterally from science to design and rarely from design to science (Lovell and Johnston 2008). This incongruity acknowledges the question: can design strategy engage and substantiate science? Additionally, within the paradigm of novel ecosystems, can design become an instrument in the toolbox of ecological restoration to reinstate cultural landscape values? In addressing these questions, it is useful to begin by reviewing how similar language is used across disciplines while accounting for variations of meaning and potential outcome, particularly within the shared binary of culture and nature.

\section{The culture of nature}

Historically, it has been accepted that a dualistic opposition between culture and nature exists (Haila 2000). In this regard, many parallels can be made to associated terminology stemming from the purely scientific realm (Kowarik 2011). For instance, Kowarik uses a nonscientific conceptual framework referring to a 'four natures approach' (Table 1) having noticeable similarities to other scientific paradigms (Ellis et al. 2013) ${ }^{c}$. In this regard, Kowarik's Nature 1 is the 'old wilderness' (pristine ecosystems), Nature 2 is the 'traditional cultural landscape' (agricultural landscapes), Nature 3 is 'functional greening' (gardens and parks), and Nature 4 is the 'new wilderness'. The latter is where both cultural and natural mechanisms begin to assert themselves, thereby creating novel ecosystems (Kowarik 2005). The ecological perspective does not differentiate between happenstance and conscientious design; therefore, the cultural describes historic usage rather than human agency (i.e., design). Consequently, Nature 4 may occur

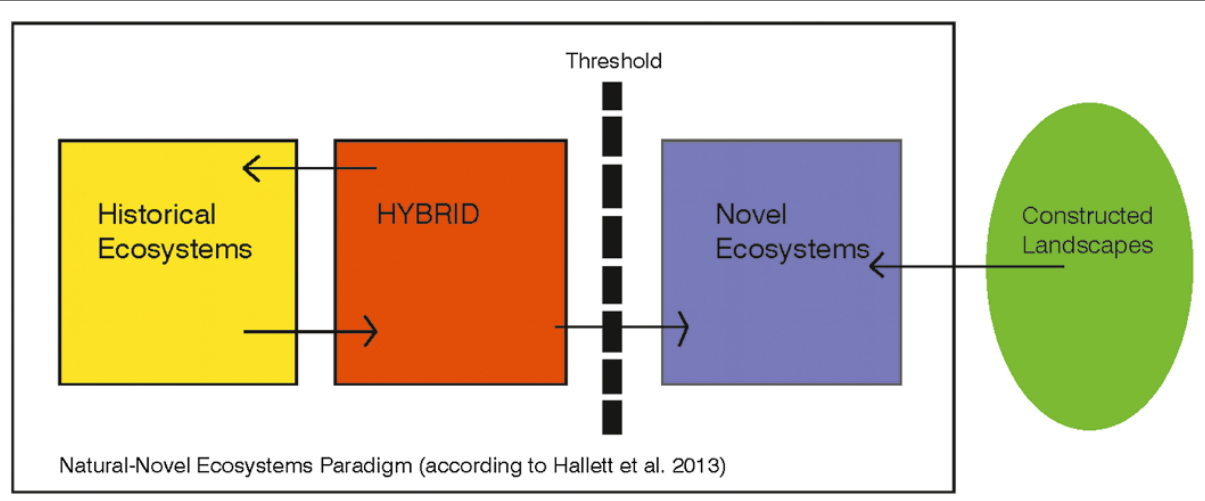

Figure 1 The role of cultural (designed) landscapes within a novel ecosystem continuum. 
Table 1 The cultures of nature

\begin{tabular}{lll}
\hline & Kowarik's four natures $^{\dagger}$ & Hunt's three natures $^{\ddagger}$ \\
\hline Nature 1 & Old wilderness & Wilderness \\
Nature 2 & Traditional cultural landscape (including agriculture) & The agrarian landscape \\
Nature 3 & Functional greenery (e.g., parks, street trees) & The garden \\
Nature 4 & New wilderness (e.g., post-industrial sites, succession woodlands) & \\
\hline
\end{tabular}

${ }^{\dagger}$ As adapted from Kowarik (2005); ${ }^{\ddagger}$ As adapted from Hunt (2000).

within 'cracks of the sidewalk' or in woodland succession on abandoned industrial sites - these may then be defined as so-called novel ecosystems. Here, the concept of novel ecosystems directly applies to urban ecosystems, since even the value of less-than-pristine landscapes can contribute to overall ecosystem function, social benefits and biodiversity conservation. Yet, by defining Nature 4 as an act of mere happenstance, the synaesthetic potential (i.e., the engagement of the senses) of landscape is not achieved. In contrast, Hunt's articulation of the Renaissance construct of the Three Natures (Table 1) finds a continuum (or 'sliding scale of cultural intervention') but posits the 3rd Nature as 'some conjunction of metaphysical experience with physical forms, specifically some aesthetic endeavour - the wish or need to make a site beautiful' (Hunt 2000). Hunt's 3rd Nature is not just about the functional amenity of landscape, but involves a considered spatial proposition that encompasses beauty and delight. It is this deliberate act to engage the sensual that is needed in creating culturally and ecologically appropriate novel ecosystems.

The translation of concepts from landscape architecture to landscape ecology is not seamless, but corresponding ideas are found in practice. For example, Latz's oft-cited wild and spirited Landschaftspark in Duisburg-Nord (Germany) exemplifies how a novel ecosystem can be purposefully designed in the 21st century. Following decades of industrial degradation as a result of coal and steel production, this site, located in the densely populated Ruhr Valley, represented 230 acres of significantly polluted landscape. Ecologically most biotic and abiotic thresholds had been irreversibly crossed, while culturally the site represented the Ruhr's industrial heritage. Conceived in 1989, the park was designed to support a regional aesthetic celebration of the Ruhr's cultural heritage as well as to create a sustainable ecology and promote economic renewal. Contaminated soils were sequestered or, where possible, mitigated through phytoremediation. The site's extensive infrastructure, including blast furnaces, foundries, bunkers, cooling towers, shops and gasometers, was retained as remnants of a cultural landscape. A biological station was established in 2005 to study and support conservation and biodiversity. With visitors engaged in activities typically found within an untamed national park or landscape reserve, including snorkelling and abseiling (Figure 2), the reconfiguration of a landscape of industrial artefacts has been aimed at introducing 'natural processes in a devastated and perverted situation. These processes work according to the rules of ecology, but are initiated and sustained by technological means ${ }^{c}$ (Latz, as quoted in Weilacher 2007). The park is a primordial cultural landscape whereby its ecological processes, concurrent with the highly artificial, have made a 'new wild' landscape, as defined by Kowarik's 4th Nature (Figure 3). Hence, by engaging play, delight and

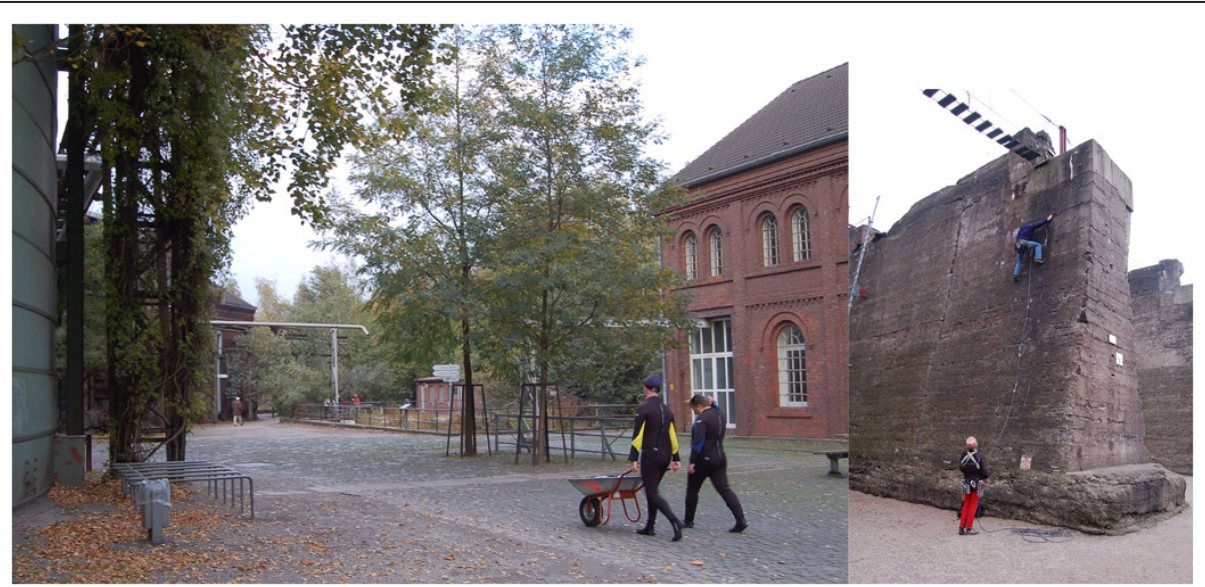

Figure 2 Landschaft Park Duisburg-Nord and some of the activities that echo those found in National Parks. The refurbished gasometer serves as a place for scuba diving and remnant walls places for climbing. 


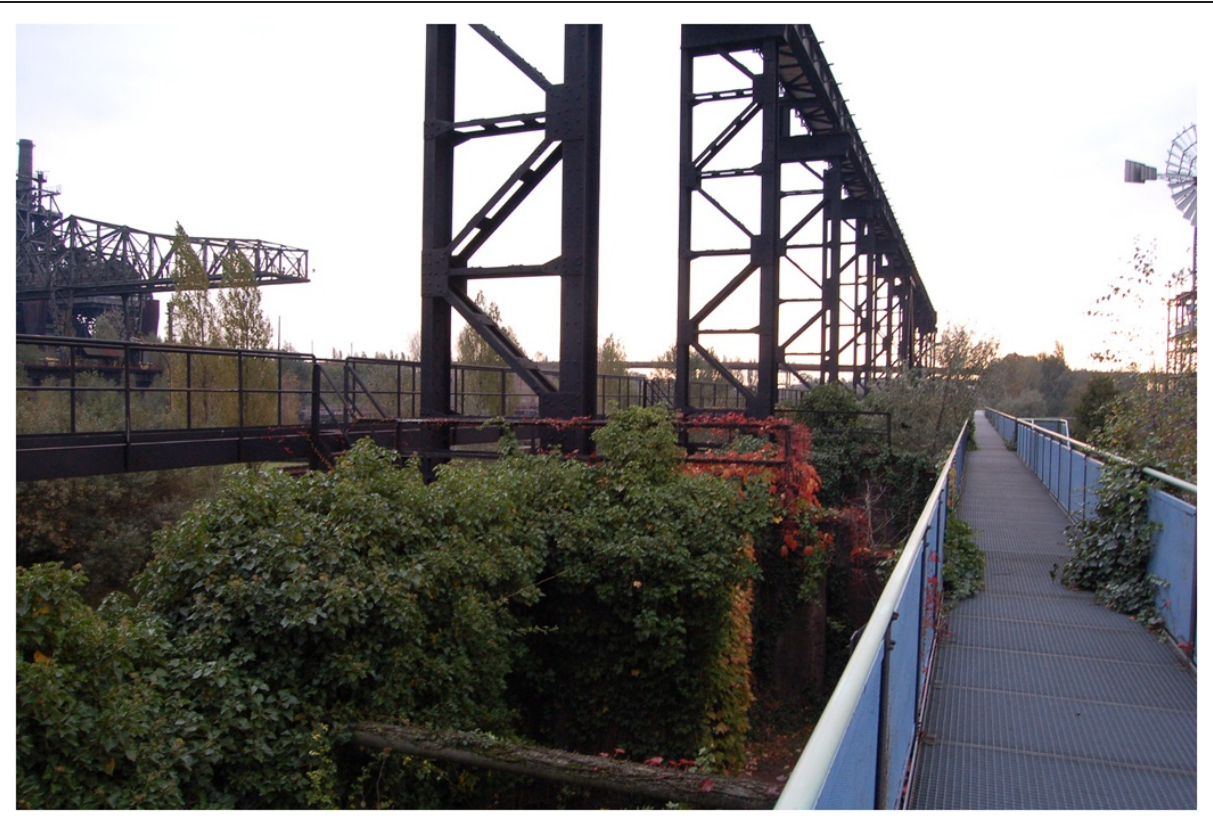

Figure 3 Landschaft Park Duisburg-Nord showing Kowarik's Fourth Nature plants returning by happenstance rather than imposition.

pleasure, this designed landscape engages what Jordan termed the 'theatre' of restoration (Jordan 1987). While the definition of novel ecosystem is extended beyond its primary ecological sense (i.e., in relation to the crossing of abiotic and biotic thresholds Hobbs et al. 2013), it exemplifies how humans can be brought closer to 'natural' ecological landscapes by engaging novel human activities rather than simply attempting to reinstate nature. Further examples of this type of engagement include:

- Ferropolis by Industrielles Gartenreich in Gräfenhainichen (Germany): A rehabilitated opencut coal mine turned open-air museum, now used for concerts and festivals;

- The Red Ribbon of Tanghe River Park by Turenscape in Qinhuangdao, Hebei Province (China): A sinuous $500 \mathrm{~m}$ long red bench along a restored river bank that interfaces human and ecological activities;

- Tanner Springs Park by Atelier Dreiseitl in Portland OR (USA): A recovered post-industrial wetland in a densely urbanized area.

In the design of these spaces, narrative, metaphor and storytelling are considered tools of landscape architecture, thereby revealing human intervention while celebrating systems renewal. The establishment of these landscapes required a significant long-term commitment to rehabilitation, as well as an acknowledgement that the final landscape is distinctly a cultural landscape, not a replica of an ecologically historic landscape. While these landscapes could represent clear beneficial elements of novel ecosystem design it remains to be seen whether these cultural endeavours can become relevant to those working in ecological restoration reciprocally with design informing science.

\section{Design in interventionist ecology}

A common feature of Duisburg-Nord Landschaftspark, Tanghe River Park, Tanner Springs Park and others is their renewed engagement as novel cultural landscapes; this engagement was directly achieved by careful design of otherwise derelict or highly degraded sites. Some proponents within ecology, specifically novel ecology, have found merit in the relevance to such engagement (Higgs 2003). These strategies find particular relevance in addressing the increasing number of sites for which there are no ecological references or that arise as an unavoidable consequence of increasing urbanization, agricultural expansion and industrialization associated within the Anthropocene. Proximity, nativeness and gardening are all strategies that ecologists have already brought into the debate (Miller 2006; Standish et al. 2013; Goddard et al. 2010a). However, these deliberations avoid some key characteristics of beloved and valued places (both natural and nonnatural), including a landscape's inherent qualities of sensuality, wonder and delight, all arguably found in the aforementioned designed landscapes. While these are not likely terms to be found within a scientific discourse, they are not entirely unheard of within the general realm of science. In writing autobiographically of their introduction to the sciences, many known and unknown scientists use descriptive words like curiosity, 
delight, pleasure, and wonder in describing their entry to the scientific world (Lightman 2006; Wilson 1984). Further historical recollection also reveals the occupation of scientists in explaining and promulgating these sensory endeavours. In sixteenth-century Europe, scientists were called together to make sense of 'a whole new reality that embraced the expanding boundaries of the known physical world and hitherto unimagined richness and complexity in terms of natural phenomena. Not only plants but also animals and minerals unknown to the ancients were waiting to be studied, described and most challenging of all - classified according to rational scientific criteria (Tomasi 2005). This confluence became physically manifest in the botanic gardens of the seventeenth century, also known as 'gardens of knowledge'. In this, scientists of the Baroque era engaged in an age of 'scientific sublimation' or a search for the sublime through scientific investigation (Tomasi 2005). A baroque quality inherent to all of this (both in the arts and science) is that of meraviglia referring to 'a sense of wonder'. In the current Anthropocenic age of rapid change due to a changing climate, the Baroque suggests a technique that writes the sensual into the systematic and merges the synaesthetic with the scientific by inscribing intervention ecology with qualities of meraviglia, creating what Lyle (1991) termed 'deep forms'. Recalling the introductory view that certain novel ecosystems could be viewed as purposefully designed landscapes that encompass both cultural and ecological values, it is proposed hereafter that this particular baroque quality could provide one possible bridge, linking and engaging the role of culture in ecological design to inform the science of ecological restoration. Accordingly, what follows is a proposition for a design strategy for the southwest of Australia, situated within the Southwest Australian Floristic Region (SWAFR) - an apparent ready canvas for novel ecosystems and systems renewal in urban areas.

\section{A landscape neo-baroque design proposition for Western Australia}

The SWAFR - an area of $302,627 \mathrm{~km}^{2}$ and home to the city of Perth - is amongst the Earth's richest in endemic species and is recognized as one of 25 global biodiversity hotspots (Myers et al. 2000; Hopper and Gioia 2004). The highly weathered and nutrient deficient soils support a rich variety of woodlands, forests, heath and bush, all well adapted to local Mediterranean weather patterns. Within Perth midstorey banksia woodlands, coastal heath and kwongan, intercepted occasionally by large wetlands, predominated historically. The ocean to the west and the longitudinal Darling Scarp to the east create perceptible boundaries for development and in turn promote an elongated urbanization pattern, north to south following the coastline. Where extant in undeveloped areas, vegetated areas remain of high ecological fidelity and unique biodiversity but are currently under threat due to urbanization commensurate to a booming mining economy and a rapidly growing population. Despite the undeniable benefits of this socioeconomic growth towards human well-being, the rate of change associated with this development has led landscape architects, citizens and conservationists (among others) to sound their concern over the planning and environmental management (i.e., by government agencies and developers) of disturbed lands and remnant landscape patches having high ecological integrity (Hobbs et al. 2011). Equally current landscape architectural and development practices do not always fit well into the complexities of the SWAFR's old climatically buffered and infertile landscapes (OCBILs, Hopper 2009). In this respect, development has generally been predicated on established northern hemisphere practices, e.g., within the context of designated young often disturbed fertile landscapes (YODFELs). As an example of such development, artificial lakes, reminiscent of those found in a verdant English countryside, are constructed into the free-draining dunes of the coastal heath. High-input landscapes, both nutrient and water demanding, are designed around these lakes, while the historical banksia woodlands and coastal heath are predominantly removed. The sloping topography of secondary dune systems is also substantially erased and replaced with terraced suburban blocks. As a consequence, the 'designed' and constructed landscapes that are replacing these (newly) historical, biologically rich landscapes bear no ecological or aesthetic resemblance to their precedents. Within adjacent residential landscapes, anthropologists have also shown how residents create 'landscapes of attachment,', constructing gardens to create a sense of belonging. Counter to the endemic landscape, this is achieved by preferencing exotic species over native (Trigger and Mulcock 2005). Urbanization, on private and public land, diminishes the footprint of the robust and biologically rich endemic landscape of the SWAFR, in turn, replacing it with constructed landscapes of lessor ecological value.

Cultural attitudes remain a critical barrier to ecologically relevant urban design, in both public and private realms. To help overcome this, specific design strategies are required in order for ecological function within landscapes to be saved as well as grown and, importantly, increased within the urban landscape. Inherent in building such a strategy is an understanding of local landscape attributes. Hopper's (2009) theory articulates strategies and hypotheses for conserving OCBIL landscapes having significant implications towards the design of urban landscapes. For this discussion, key strategies include: the minimization of nutrient inputs, minimizing the importation of alien plants 
as well as animals and disease, and the planting of locally endemic species. Such practices are also critical in supporting and increasing endemic fauna (Bhullar and Majer 2000) (Davis et al. 2008). The ensuing strategy builds on these foundations.

Following Higgs' notion of focal practice, where 'restoration... nourishes nature and culture,' the proposed design strategy engages historical concepts from the Baroque with local OCBIL restoration practices to stem the loss of biodiversity as well as qualities of place (Higgs 2003). The aims of this strategy are as follows:

1. To overcome the nature-culture binary (including the local native-exotic debate, (Shackelford et al. 2013; Haila 2000);

2. To derive termed focal restoration (Higgs 2003), based on this specific place, not translated from practices established in the northern hemisphere;

3. To reinvest ecological restoration practices with the quality of meraviglia;

4. To demonstrate how design strategies can work with ecological principals in creating ecologically regenerative landscapes.

In articulating a neo-baroque strategy, it is essential to understand that, in this instance, what is derived from the Baroque is a technique, not a style. Techniques invoking the Baroque can easily be tainted by the term's historic and stylistic connotations. But if a baroque strategy is understood as a methodology, a simple comparison of baroque qualities with the qualities of a restored ecosystem relays important commonalities (Table 2). The goal in a neobaroque ecology is to transcend both the prescriptive within the ecological and the superficial veneer of style to reinvest the landscape with that most important of baroque characteristics - meraviglia - a state of wonder. Inspired by discussions of the conceptual baroque (Calabrese 1992) and guided by Wofflin's considerations of the formal qualities of the seventeenth-century baroque (Lambert 2004), contemporary neo-baroque techniques can be derived for ecological application. This application is manifest in several ways: a preference for movement over places of repose; an affinity for the multiplication of surfaces, contours and folds; and the marvellous use of the chiaroscuro or creating a heightened sense of ephemerality through the mixing of light and shadow. Complexity, allegory, dynamism, multiplicity are all techniques within the toolbox of the baroque, many finding direct correlation with the techniques and aims of ecosystem ecology. In restoring a landscape, ecologists strive to restore or implement key mechanisms of a landscape system (Table 2). According to Hobbs and Norton (1996), the ecologist seeks to increase heterogeneity of species, creating or preserving a complexity of variables made up of different landscape components. Baroque technique can underpin and supplement the performance of basic ecological processes through the manipulation of spatial constructs that positively affect abiotic and biotic conditions. The dynamic complexity of a landscape can serve in preserving water and abetting nutrient transfer by altering temperature, moisture, wind speed and insulation. Ecologists strive to emulate patterns within the horizontal and topographic arrangement of a system's components. Recognizing this, the constructed landscape mosaic becomes baroque: painterly rather than pictorial, preferencing movement over flaccid minimalism, and wedding the baroque 'dynamic integration of composition' (Conan 2005) with what ecologists term 'dynamic resilience' (Hobbs and Norton 1996). Baroque technique, constructed with local species, assures that a designed landscape within the SWAFR strives to become a landscape of depth serving a multitude of ecological functions - ecosystem delivery, habitat creation - but also includes the cultural function of aesthetic pleasure.

\section{Towards a neo-baroque ecology}

In creating constructed novel ecosystems within the OCBIL landscapes of Western Australia, the techniques within a baroque toolbox succour the local by embracing and enhancing intrinsic ephemera and site specificities. Already, baroque attributes are inscribed in the Western

Table 2 Comparison of neo-baroque ecology and ecosystem restoration

\begin{tabular}{|c|c|}
\hline Wofflin's attributes of the baroque style ${ }^{\dagger}$ & Hobbs' ecosystem attributes to be restored ${ }^{\ddagger}$ \\
\hline Supplanting of a linear style, which produces a sense of movement & Composition: species present and their relative abundances \\
\hline $\begin{array}{l}\text { A heightened sense of transience through the mixing of } \\
\text { light and shadow (chiaroscuro) }\end{array}$ & $\begin{array}{l}\text { Structure: vertical arrangement of vegetation and soil } \\
\text { components (living and dead) }\end{array}$ \\
\hline Monumentality - a love of the grand, the massive, the sublime & Pattern: horizontal arrangement of system components \\
\hline $\begin{array}{l}\text { An expressive tendency towards the multiplication of surfaces, } \\
\text { contours and folds }\end{array}$ & Heterogeneity: a complex variable made up of components \\
\hline \multirow[t]{2}{*}{ A preference for movement in place of repose } & $\begin{array}{l}\text { Function: performance of basic ecological processes } \\
\text { (energy, water, nutrient transfers) }\end{array}$ \\
\hline & Dynamics and resilience: successional processes, recover fror \\
\hline
\end{tabular}

${ }^{\dagger}$ As adapted from Lambert (Lambert 2004); ${ }^{\ddagger}$ As adapted from Hobbs and Norton (1996). 
Australian landscape. The flora, while at times prickly, is also mellifluously rococo in detail and form. From root clusters to regenerating lignotubers after a bush fire, an inherent exuberance is built into this detailed and complex landscape. In Western Australia, the wind is a steadfast daily ritual, with cooling summer sea breezes alternating with drying desert easterlies. The sun blasts its unrelenting rays and in the summer one lives in the perpetual shimmer heat of the west. Currently these local qualities are taken for granted, all but ignored within the creation of civic and private landscapes. Engaging the baroque, landscapes of chiaroscuro can be built that - to use the language of pleasure - dance between sun and shadow, creating landscapes that sway and dance with the delivery of the cooling afternoon breeze and slowing hot desert blasts. Structurally, one can begin to impose shade structures that break the wind, allowing a flat surface to be broken into a chiaroscuro of dark and light. Within open landscapes of reconstruction, these structures serve as seed catchers as well as constructs that bring shadow and pause into the landscape. Leeward to the wind, significant microenvironments for moisture harvesting and preservation become possible and boundaries, in turn, become more permeable, allowing for the flow and mingling of invertebrates and vertebrates (Figure 4). Using the locale's endemic botanical richness, plant palettes are created that are exuberant of foliage, privileging vegetal excess in the name of increasing species richness (Figure 5). Hand in hand with this, there is the potential to achieve a complexity of habitat, increasing species diversity both botanically and zoologically.

In both design and ecology, scale matters (Menz et al. 2013). In this regard, baroque strategies function across scales; as a technique, the baroque is flexible and can be applied to the large park, the linear verge or the garden. Within the OCBIL landscape, where every patch is significant, the addition of patches increases the footprint of ecologically relevant landscapes. Embracing a neo-baroque ecology, one can facilitate this increase, in essence crowdsourcing patches by adding aesthetic function to their value. Additionally by creating gardens of pleasure that are also manifest with ecological depth, horticultural practice can begin to serve the need of systems, addressing some of the constraints, including financial and social, identified by many ecologists (Miller and Hobbs 2007). In recreating the bush, there is an underlying sense that the space does not need to be maintained. If a landscape is treated as a garden, maintenance and care become intrinsic components (Janzen 1998; Goddard et al. 2010b). In reconnecting landscape systems with a regenerative design of the Third Nature, a neo-baroque ecology resonates the historic rapport between scientist and garden architect in the temporal Baroque period. In making these propositions, there is a reconnection of the garden of pleasure with

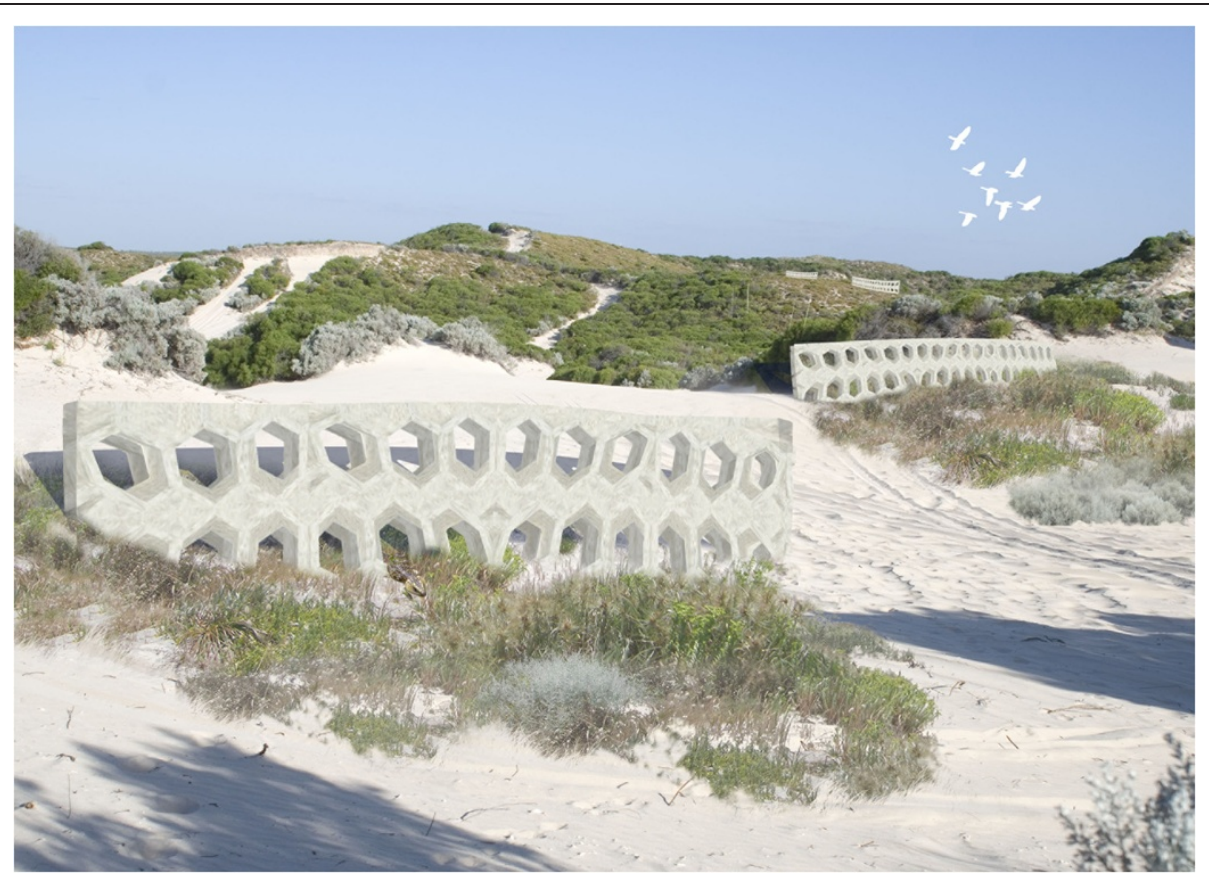

Figure 4 Inspired by the processes that facilitate the growth of coral, this 'fence' serves as permeable boundary marker as well as 'dune catcher', helping to retain blowing sands in the re-growth of dunes. 

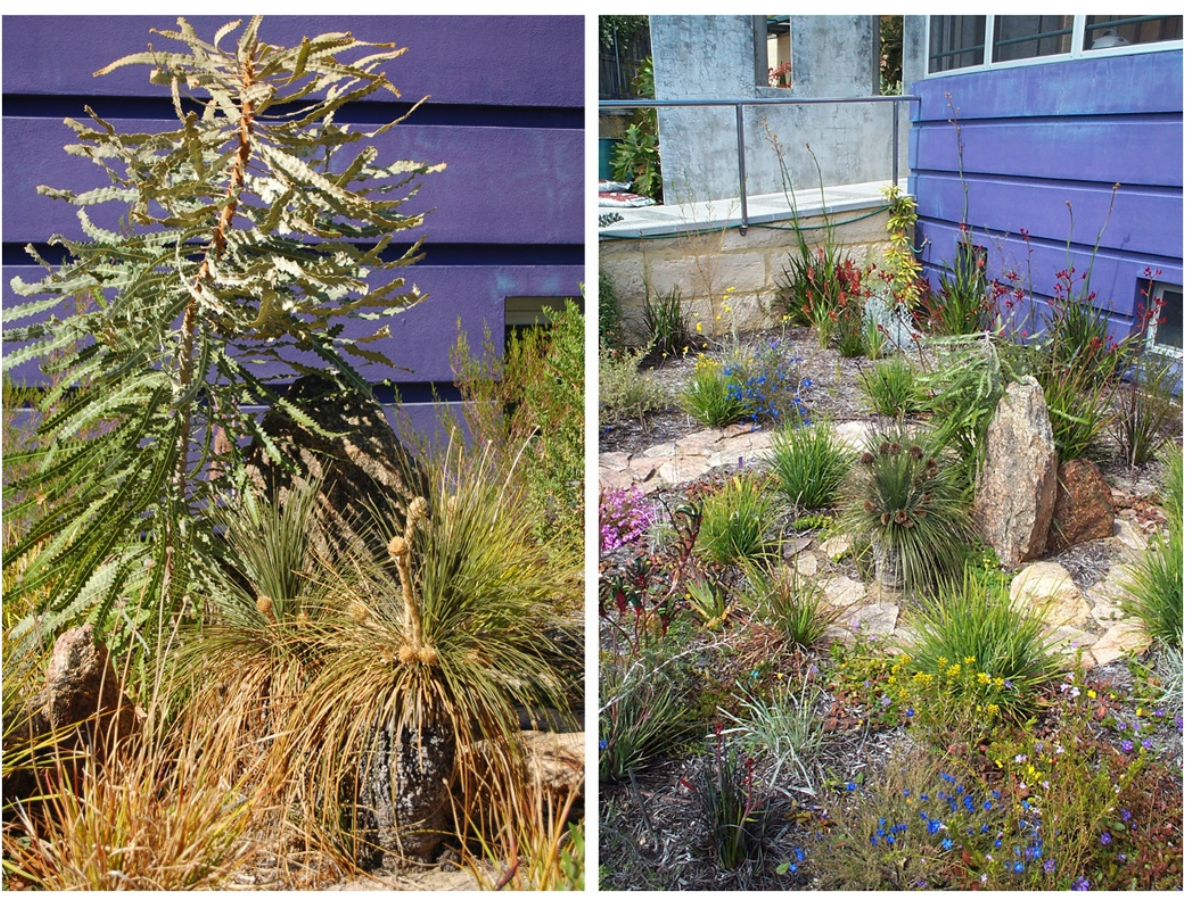

Figure 5 An example of the exuberance in detail, heterogeneity and form of the OCBIL flora.

environmental good, achieving a 'scientific sublimation' (Conan 2005) and, by exploiting the mutability of taste, a neo-baroque ecology allows for ecological restoration in an expanded field.

\section{Conclusions}

Baroque ecologies: predictable outcomes or ecological conjecture?

In Duisburg-Nord, the industrial remnants were heavy and overwhelming, with ecological systems working around and between industrial (human) artefacts. In other landscapes with heavily modified ecologies - mining, salinity, urbanization - design can mark the hand of human intervention, but then return the landscape to an amalgamation of historic ecologies and cultural handprints. This design proposition, one of neo-baroque design strategies, must, like all experiments, be tested. Best practice for ecological restoration changes over time with increased knowledge and runs on the board. Ecologists are aware that spatial construction (the image of the landscape) does not necessarily predict ecological function (Doley and Audet 2013; Majer et al. 2013). A neo-baroque landscape ecology may seem to some scientists to be an extreme move. But with the decreasing footprint of landscapes with extant ecological systems, we collectively, scientist and maker of place, must find every means to regenerate ecological systems within both natural and cultural landscapes. While some may find the idea of a neo-baroque ecology to be one of hubris, close inspection will find a humility and respect for the particularities of Southwestern Australia's OCBIL landscape and its intricate systems. Design plays a role where ecological thresholds have been created through human intervention, such as salinity, mining or fragmentation. Equally, the baroque concept of meraviglia transcends professional boundaries and is often inherent in 'natural' landscapes. With an open and critical discourse as well as a professional cross-pollination of language, technique and strategies (here in landscape architecture and restoration ecology), there is the potential of increasing the footprint of landscapes capable of delivering ecosystem function.

\section{Endnotes}

${ }^{\mathrm{a}}$ Landscapes containing new assemblies of abiotic or biotic system components and then forming stable alternative ecological states (Hobbs et al. 2006, Hobbs et al. 2009; Hobbs et al. 2013).

bIan McHarg's seminal book, Design with Nature, introduced landscape architects to a systematic method for 'reading' and interpreting landscapes. His layering method was an antecedent to Geographic Information Systems (McHarg and Mumford 1969).

${ }^{\mathrm{C}}$ In his global depiction of the biogeography and biodiversity of anthromes (i.e., anthropogenic biomes) and novel ecosystems, Ellis (2013) similarly refers to a 
continuum from wildlands (or wild habitat), through semi-natural anthromes (or novel habitat), to used anthromes (used rangeland, cropland, villages and dense settlements).

\section{Abbreviations}

OCBIL: Old climatically buffered and infertile landscape; SWAFR: Southwest Australian Floristic Region; YODFEL: Young often disturbed fertile landscape.

\section{Competing interests}

The author declares that she has no competing interests.

\section{Acknowledgements}

This title pays homage to Rosalind Krauss' seminal essay 'Sculpture in an Expanded Field' (Krauss 1979). As sculpture moved away from being solely three-dimensional works in a gallery, Krauss expressed the expanded field as lying between - 'not landscape' and 'not architecture'. I would like to acknowledge the open and generous discourse of the editors of this journal, Patrick Audet and Michael Perring. What merits they have found in this cross-disciplinary strategy, they have graciously underpinned with scientific enthusiasm and precision.

\section{Received: 6 May 2013 Accepted: 5 December 2013}

Published: 26 December 2013

\section{References}

Barrett TL, Farina A, Barrett GW (2009a) Aesthetic landscapes: an emergent component in sustaining societies. Landscape Ecol 24(8):1029-1035

Barrett TL, Farina A, Barrett GW (2009b) Positioning aesthetic landscape as economy. Landscape Ecol 24(3):299-307

Bhullar S, Majer J (2000) Arthropods on street trees: a food resource for wildlife. Pac Conserv Biol 6171

Calabrese O (1992) Neo-Baroque. Princeton University Press

Conan M (2005) Baroque garden cultures: emulation, sublimation, subversion, vol 25. Dumbarton Oaks, Washington

Davis RA, Brooker L, Roberts JD (2008) Ecological Linkages and Urban Fauna at Risk on the Swan Coastal Plain. University Western Australia, Perth, WA, Final Report

Doley D, Audet P (2013) Adopting novel ecosystems as suitable rehabilitation alternatives for former mine sites. Ecol Processes 2(1):1-11

Ellis EC, Kaplan JO, Fuller DQ, Vavrus S, Goldewijk KK, Verburg PH (2013) Used planet: A global history. Proc Nat Acad Sci 110(20):7978-7985

Felson AJ, Pickett STA (2005) Designed experiments: new approaches to studying urban ecosystems. Front Ecol Environ 3(10):549-556

Gobster PH, Nassauer Jl, Daniel TC, Fry G (2007) The shared landscape: what does aesthetics have to do with ecology? Landscape Ecol 22(7):959-972

Goddard MA, Dougill AJ, Benton TG (2010a) Scaling up from gardens: biodiversity conservation in urban environments. Trends Ecol Evol 25:90-98

Goddard MA, Benton TG, Dougill AJ (2010b) Beyond the garden fence: landscape ecology of cities. Trends Ecol Evol 25(4):202-203

Haila Y (2000) Beyond the nature-culture dualism. Biol Philosophy 15(2):155-175

Haila Y (2007) Enacting landscape design: from specific cases to general principles. In: Lindenmayer DB, Hobbs RJ (eds) Managing and designing landscapes for conservation: moving from perspectives to principles. Blackwell, Malden MA, pp 22-34

Higgs E (2003) Nature by design: people, natural process, and ecological design. MIT Press, Cambridge, MA

Hobbs RJ, Norton DA (1996) Towards a conceptual framework for restoration ecology. Restor Ecol 4:93-110

Hobbs RJ, Arico S, Aronson J, Baron JS, Bridgewater P, Cramer VA, Epstein PR, Ewel JJ, Klink CA, Lugo AE, Norton D, Ojima D, Richardson DM, Sanderson EW, Valladares F, Vil M, Zamora R, Zobel M (2006) Novel ecosystems: theoretical and management aspects of the new ecological world order. Global Ecol Biogeography 15(1):1-7

Hobbs RJ, Hallett LM, Ehrlich PR, Mooney HA (2011) Intervention Ecology: Applying Ecological Science in the Twenty-first Century. Bio Sci 61(6):442-450. doi:10.1525/bio.2011.61.6.6

Hobbs RJ, Higgs E, Harris JA (2009) Novel ecosystems: implications for conservation and restoration. Trends Ecol Evol 24(11):599-605
Hobbs RJ, Higgs ES, Hall C (2013) Novel ecosystems: intervening in the new ecological world order. John Wiley \& Sons

Hopper S (2009) OCBIL theory: towards an integrated understanding of the evolution, ecology and conservation of biodiversity on old, climatically buffered, infertile landscapes. Plant Soil 322(1):49-86

Hopper SD, Gioia P (2004) The Southwest Australian Floristic Region: evolution and conservation of a global hot spot of biodiversity. Annu Rev Ecol Evol Syst 35:623-650

Howett C (1998) Ecological Values in Twentieth-Century Landscape Design: A History and Hermeneutics. Landscape Jrnl 17(Special_Issue):80-98, doi:10.3368/lj.17.Special_Issue.80

Hunt JD (2000) Greater perfections: the practice of garden theory. University of Pennsylvania Press, Philadelphia

Janzen D (1998) Gardenification of wildland nature and the human footprint. Sci 279(5355):1312-1313

Jordan WR (1987) Restoration and management as theater. Ecol Restor 5(1):2

Kowarik I (2005) Wild urban woodlands: towards a conceptual framework. In: Kowarik I, Körner S (eds) Wild urban woodlands: new perspectives for urban forestry. Springer, Berlin, pp 1-32

Kowarik I (2011) Novel urban ecosystems, biodiversity, and conservation. Environ Pollut 159(8-9):1974-1983

Krauss R (1979) Sculpture in the expanded field. October 8:31-44

Lambert G (2004) The return of the baroque in modern culture. Continuum, London

Lightman A (2006) A sense of the mysterious: science and the human spirit. Vintage, New York

Lovell ST, Johnston DM (2008) Creating multifunctional landscapes: how can the field of ecology inform the design of the landscape? Front Ecol Environ $7(4): 212-220$

Lyle JT (1991) Can floating seeds make deep forms? Landscape Jrnl 10(1):37-47

Majer JHB, Gohr T, Mounsher L, Grigg A (2013) Is thirty-seven years sufficient for full return of the ant biota following restoration? Ecological Processes 2(19)

McHarg IL, Mumford L (1969) Design with nature. American Museum of Natural History, New York

Menz MH, Dixon KW, Hobbs RJ (2013) Hurdles and opportunities for landscape-scale restoration. Sci 339(6119):526-527

Miller JR (2006) Restoration, reconciliation, and reconnecting with nature nearby. Biol Conserv 127(3):356-361

Miller JR, Hobbs RJ (2007) Habitat restoration - do we know what we're doing? Restor Ecol 15(3):382-390

Musacchio LR (2009) The scientific basis for the design of landscape sustainability: a conceptual framework for translational landscape research and practice of designed landscapes and the six Es of landscape sustainability. Landscape Ecol 24(8):993-1013

Myers N, Mittermeier RA, Mittermeier CG, da Fonseca GAB, Kent J (2000) Biodiversity hotspots for conservation priorities. Nature 403(6772):853-858

Shackelford N, Hobbs RJ, Heller NE, Hallett LM, Seastedt TR (2013) Finding a middle-ground: The native/non-native debate. Biol Conserv 158(0):55-62, http://dx.doi.org/10.1016/j.biocon.2012.08.020

Standish R, Hobbs R, Miller J (2013) Improving city life: options for ecological restoration in urban landscapes and how these might influence interactions between people and nature. Landscape Ecol 28:1-9

Thayer RL (1998) Landscape as an ecologically revealing language. Landscape J 17(Special Issue):118-129

Tomasi LT (2005) Garden of knowledge and the Republique des Gens de Science. In: Conan M (ed) Baroque Garden Cultures: Emulation, Sublimation, Subversion, vol 25. Dumbarton Oaks, Washington

Trigger D, Mulcock J (2005) Native vs exotic: cultural discourses about flora, fauna and belonging in Australia. WIT Trans Ecol Environ 2:1301

Weilacher U (2007) Syntax of landscape: the landscape architecture of Peter Latz and partners. Birkhäuser, Basel

Wilson EO (1984) Biophilia. Harvard University Press, Cambridge MA

Windhager S, Steiner F, Simmons MT, Heymann D (2010) Toward Ecosystem Services as a Basis for Design. Landscape J 29(2):107-123

doi:10.1186/2192-1709-2-35

Cite this article as: Sack: Landscape architecture and novel ecosystems: ecological restoration in an expanded field. Ecological Processes 2013 2:35. 